and Mr. Tutton. This substance has been shown by the exhibitors to be represented by the formula $\mathrm{P}_{4} \mathrm{O}_{8}$.
It crystallizes in monoclinic prisms melting at 2555 deg., and boils in an atmosphere of nitrogen or carbon dioxide at 173 deg. Cold water dissolves it with extreme slowness, forming phosphorous acid. With hot water,
strong caustic alkalies, chlorine, bromine, and alcohol, it reacts with great energy, generally with inflammitures, into phosphoric oxide, and under diminished phorus. No ozone, however, is formed. At slightly phorus. No ozone, however, is formed. At slightly higher temperatures the oxidation is brought about in
stantly with production of flame. Phosphorous oxide
possesses the smell usually atributed to phosphoris possesses the smell usually a atributed to phosphorus, manufactories. It is highly probable, as schonbein surmised, that the element phosphorus is without
smell, and that the smell ordinarily perceived is due to a smell, and that the smell ordinarily perceived is due to a
mixture of ozone and phosphorus oxide. Phosphorus
oxide is highly poisonous. and it is not improbable that phosphorus necrosis is caused by this substance.

Photographs of the spectrum of the nebula in Orion,
phibited by Prof. J. Norman Lockyer, F.R.S. These
photophs were taken in February with the thirtyphotographs were taken in February with the thirtyfrom two to three hours. The one taken with a three
hours exposure (February 10) shows about 50 lines be tween $\lambda .500$ and $\lambda .373$, but many of them are only visiHenry Draper memorial photograph of the spectrum of P Cygni was shown for comparison, and it was seen the nebula. This argues in favor of the view that
stars with bright-line spectra are of a nebulous char-

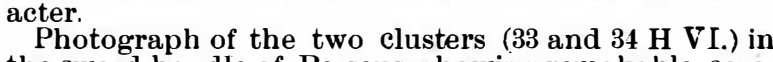
the sword handle of Perseus, showing remakable coronal and festoon-like groupings amiong the stars on sevRoberts. These clusters are quite free from nebulosit y, which Mr. Roberts has photographed; for those clus-

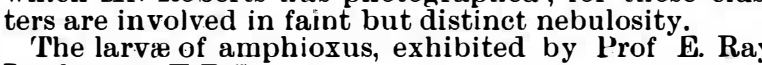
Lankester. F. R.S.
A selection from the butterflies collected in tha great equatorial forest of Africa by Mr. William Bonny.
of Mr. Stanley's staff, exhibited by Mr Henley Smith. Little was known of the Lepidoptera of this part of Africa; few of the species collected by Mr. and nine are new to science. The collection includes, pili, Zalmoxis. and many west African species.

Collection of iridescent crystals of chlorate of potash to illustrate the production of color and its intensifica-
tion by reflection from multiple thin plates, exhibited by Dr. Alex Hodgrinson. Dr. Alexander Muirhead exhibited : (1) some pat-
terns of Dr. Lodge's lightning protector for cables and
for telegraphic work generally. In these instruments a series of air gaps, separated by self-induction colls are offered to the lightning or other high tension cur-
rents which have got into the line. The greater part rents which have got into the line. The greater part
of the flash jumps the first air gap, most of the residue jumps the next, and so on. until after four or five dilunest insulation, or appreciably affect even a delicate (2) Muirhead's portable form of the Clark standard cell, in cases. with thermometer.-(3) Standard condenser, (4) Setof Thom cepacity key; suitahle for Dr.

Specimens of aluminum and alloys manufactured by the Aluminum Company, limited, exhibited by Sir Henthe E. Roscoe, F. R.S. Pigs of aluminum, 99 per eent.
pure. Castings in aluminum, rough and finished. Specimens of aluminum, soldered. Aluminum wire,
sheet and drawn rod. Aluminum medals, plain and gilt. Cast aluminum bronze and brass, showing $(a)$ tensile strength and elastic limit ; $(b)$ twisting stress
(c) thrusting stress, long specimens ; $(d)$ thrusting stress, rough. Ten per cent. aluminum bronze, twisted cold.
Five per cent. aluminum bronze, worked hot and cold. Aluminum brass, worked hot and cold. Aluminum bronze and brass sheet.

from,Egyptand Assyria, exhibited by Dr. and bronze

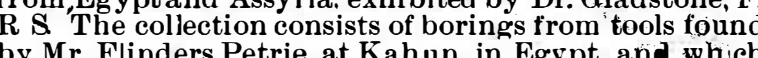
by Mr. Flinders Petrie, at Kahun, in Egypt, and which
belong to the XII. Dynasty-about B. 2500 ; also from other tools found at Gorub, which belong to the fragments of Egyptian bronze figures from Bubastis, and of Assyrian bronze from the gates of the palace of
Shalmanezer II., at Balawat, about
B. C. $84 \%$, as well Shalmanezer II., at Balawat, about B. C. 84!, as well
as two pieces of slag from the old copper mines of the Sinaitic peninsula, which were worked by the Egyp
tians in very early times, and discontinued after the XVIII. Dynasty. The principal point illustrated is the fact that the earliest metal implements were of copper, containing a very little arsenic and tin tin was added to the eopper in increasing proportions Mr. Percy Newberry exhibited by permis sion of Mr. W. M. Flinders Petrie: (1) Three pages of an ancient twenty-fifth century before Christ. This papyrus, together with a nuinber of others of the same date. referring to miscellaneins subjects (letters, legal docu ments, accounts, a fragmentary treatise on matheFlinders Petrie, during excavations in a ruined town
of the XII. Dynasty, at Kahun, in Central Egypt. It of the XII. Dynasty, at Kahun, in Central Egypt. It contains directions for the use of midwives, written in
black and red ink, in hieratic characters (a cursive or written form of hieroglyphics).
'Ihe black ink is used in the body of the work for the symptoms. diagnoses. and prescriptions, and the red ink is used at the heads of the sections. 'I'he following translation of the last two and a half
lines of the first page will serve to show the kind of directions given in this ancient work:
"Treatment of woman* who is pained in her legs and of solids, and afterward readily admit the ether in the arl her limbs, as one who is beaten. Say with re- . estimation of fat.
The material which I have found to answer best for with regard to her * thus: Let her eat grease until she this purpose is the so-called " absorbent gauze," also (2) Facsimile of an unpublished papyrus preserved known as " bleached hospital. gauze," used for surgical (2) Facsimile of an unpublished papyrus preserved dressings. It is a light, open mesh cotton fabric, having written in the Egyptian hieratic writing of the XIX.
Dynasty (B. C. 1400-1200). This papyrus is chiefly eresting from the fact that it cuntains prescription Dy the ancient copyist) to have dated frou the IV.
ynasty (circa
B. C. 4000). Facsimiles of these two papyri, together with translations, notes, etc., will
hortly be published, under the editorship of Mr. F. Li. Egyptian spear head of bronze, bearing the name
riff and and titles of Kames, a king at the end of the XVII. ynasty (circa $1750 \mathrm{~B}$. C.) exhibited by Dr. John Evans,
reas. $\mathrm{R}$. The blade is cast, and the socket is made hammered bronze, and these two pieces that form M.I. Richard Freres, Paris, exhibited:(1) Continuousy recording hair hygrometer. This is the latest form ontinent, owing to its working satisfuct irily when Saussures instruments more than one hair was used, ord. In the present hygrometer, the expansion and which leaves on a paper-covered raise and lower a pen which leaves on a paper-covered cylinder a continuous
record of the humidity of any position, garden or sick
room in which it may be placed.

(2) Curves produced by the anemometers on the sum-
mit of the Eiffel tower, and on that of the Central Meteorological Office at Paris. These show (1) that the average velocity of the wind on the top of the $t$ ( w wer
(994 feet) is about three and a half times that at $6(j$ feet and (2) that the hour of greatest average velocity on the summit was eleven P. M.. whereas at 66 feet (as at
most observatories) it was one P. M.; so that the times of maximum and minimum are alinost precisely re ersed.

(3) Isochronous regulatnr for electrie contacts. An
strument for making and breaking electrical contact at equal intervals of time.

Chætopodæ, Medusæ, Ascidians, Nudibranchs, and other lnvertebratæ, prepared as lantern slides, show-
ing not only the general form. but also much of their ing not only the general form. but also much of their
anatomy, exhibited by Mr. H. C. Sorby. F R.S. The success of the method depends on the fact that whe dries first. and adberes firmly, so that on further dry comes thinand flat. and shows like a drawing project ed on the plane of the glass.

In many cases the natural color is well seen, but in
other crses artificial staining is used which brins the anatomical structure to great advantage. In some cases the specimens are best seen by refl'cted light, and it is then well to use a photographic slide, taken under
such conditions. Some details may also be brought veloped photograph. - Nature.
velogeater advantage by m

AN IMPROVED COIL FOR MILK ANALYSIS. By Charles Rice, New York.

THE advantage of employing the so-called Adame coil (of thick blotting paper) in the estimation of milk nized; careful trial experiments having shown that, by from milk than by any other method.
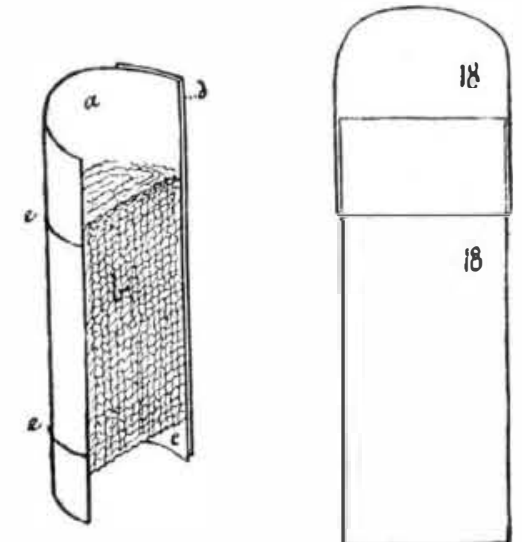

RICE'S MILK COIL AND WEIGHING TUBE.

While this fact is undisputed, there remain, however lative, which not seldom inconvenience the operator.
These drawbacks arise both from the material the coi is usually made of and from its shape.
The coils are made of thick blotting paper, the kind generally preferred being that known as "white demy
blotting, mill $428,38 \mathrm{lb}$." The best "Treasury "blotting paper is also used. Now, unless the coil is made
rather loosely, which is accomplished sometimes by rolling up a thread with the strip of paper, it is not always easy to cause the milk to sink into the coil with
suffient rapidity. Moreover, the shape at either end is not conducive to a rapid absorption, and there is not
seldom a loss from milk running down the side or es seldom a loss from milk running dow

Several modifications of Adaus' coil have been proposed from time to time, one involving the use of asbes
tos, another that of cotton, but on trial I have found os, another that of cotton, but on trial
A good milk coil, or cartridge, should possess the following properties
1. It should ha

amount of the milk taken for analysis (say 5 to $10 \mathrm{gmo}$ ) 等 2 . It should be so porous that it will readily permit
of loss. escape of water, during drying, for the estimation * In red ink. about $1 \frac{1}{4}$ av. ounces per \&quare yard.
The milk coils, or cartridges, which I have been in the habit of using, consist of a small roll of this gauze of preparation is as follows: fold it twice in one direction to reduce it to $36 \times 9$ in.,
then fold it upon thelong side in laps of $13 / 4$ in. in width, of 1 yard in length and about $13 / 4$ to $1 \% / 8$ in. in width, Now begin toroll the strip upon the narrow end. like a bandage, but not too tight, until about 5 or $51 / 2$ in. of
the gauze have been rolled up: cut the slip slantingly-
that is, not perpendicular toits body, but under an angle, so as not to cause " bunching " when wrapped in pager. Place the roll upon a strip of thick blotting paper 4 in. long and $23 / 4$ in. wide, and roll the latter over it so
as to have it (the paper) project at one end about onefourth inch over the gauze coil and about three-fourths inch at the other; then tie the coil with two threads.
It will thus be $23 / 4$ in. long and about $7 / 8$ in. in diameThe cut represents a section of one of these coils, $b$ being the gauze coil, $a$ and $c$, respect ively, the larger and
smaller free compartment, $d$ is the overlap of the paper cover, and $e e$ the strings.
The larger compartment $(a)$ of this cartridge serves as tested is poured at once. A coil of this kind-intended
for the smallest size of Soxhlet's extractor-will easily take from 8 to $10 \mathrm{gml}$. of milk, and the latter will never
entirly soak down to the bottom of the paper wrapper. If it should soak to the bottom of the gauze coil, this of the paper.

These coils may easily be prepared in quantity, then
extracted in ether, and kept in a drying oven, so as to be ready for instant use.

I am in the habit of using very light glass weighing
tubes, with snugly fitting covers, each being numbered both on the body and on the cap. A cartridge, perfectsubsequent weighings of it are made in the same tube. The milk to be examined is weighed in a separate stop-
pered graduated tube, then a suitable guantity of it, judged by guess and experience-corresponding to say about $8 \mathrm{gm} .-$ is poured into the compartioent $a$ of the
coil, which had previously been taken from the weigh. ing tube. The graduated tube is weighed again, and sis. The col at once absorbs the milk, and is then transferred on a capsule to the drying oven. When
dry it is weighed for determination of solids, and the fat then determined by extraction with ether in the usual manner.
The size of these cartridges may, of course, be varied
according to the size of the extractor in which they are

I am quite certain that those who will try the gauze
coils will prefer them to anything else heretofore proposed.-American Druggist.

\section{SOAP ANALYSIS.}

THis branch of analytical work may be successfully cultivated by any pharmacist, provided he lives in a district where the use of quantities of soap for the pur-
poses of the cloth manufacturer is on a scale which
would secure an amount of analy sesthat would be likely to return reasonable compensation for his time and trouble. Private families rarely require their soap analyzed, being content to take on trust the assertiol' accurate knowledge derived from personal experience and observation.

Soap is extensively used in every manufacturing be of a uniform character. This can only be ascertained by analysis; and howerer much confidence soap, there is, in the nature of things, frequently occasion to have recourse to the chemist. For the purpose
of ascertaining the value of soaps as detergents, the ollowing points must be kept in view : Whether the ployed in the general cleansing of fabrics; and for the and colors of such fabrics must be taken into considera. 'The composition of soap from a chemical point of $v i e w$ is essentially that of a salt-that is the product of
the chemical union of a base and an acid. The acid constituent of soap is generally a mixture of st earic,
palmitic, and oleic acids, the basic portion being either palmitic, and oleic acids, the basic portion being either
potassium or sodium. The potassium salt of these acids alkali may exist in several conditions, either combined with the fatty acids, or uncombined, as carbonate, or the soap has been made, and its age, determine to a arge extent the condition in which the alkali occurs. Soap analysis is partly gravimetric and partly volu-
metric. For the former a balance is necessary, but as

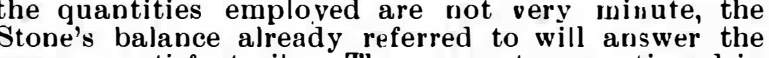
purpose satisfactorily. The apparatus mentioned in in addition to these a water bath will be required. Standard solutions of hydrochloric and nitric acids are pecessary, and these are most collvenient when pre
pared of normal strength. Normal hydrochloric acid pared of normal strength. Normal hydrochloric acid
ought to contain exactly 36.37 grains of pure acid in
1,000 grain measures, and is prepared as follows: Into a 10.000 grain flask are placed 1,808 grains of hydroch loric acid s. g. 11 , and distilled water is added till the 10,000 grain mark is reached, at the required temperature $\left(16^{\circ} \mathbf{C}\right.$.) This furnishes a solution approximately normal, with an accurately weighed quantity of pure sodium
monocarbonate. The solution of nitric acid requires so that when the whole is folded it will present a strip a funnel, into which the full quantity of the milk to be town for thepurpose of cleansing and purifying the fato-
rics, and it is of the utmost consequence that it should s usually known as soft soap, and the sodium salt as 